\title{
Systemic dissemination of glioblastoma: literature review
}

\author{
(D)/uliana Arcangelo Di Vita Carvalho ${ }^{1}$ \\ (i) Caroline Chaul de Lima Barbosa 2,3 \\ (iD) Olavo Feher ${ }^{2,3}$ \\ (iD) Marcos Vinicius Calfat Maldaun ${ }^{4,5}$ \\ (iD) Veridiana Pires de Camargo ${ }^{2,3}$ \\ (iD) Fabio Y. Moraes ${ }^{6,8}$ \\ (iD) Gustavo Nader Marta 7,8
}

\begin{abstract}
1. Department of Radiation Oncology - Oncologia Centenário São Leopoldo - Rio Grande do Sul, Brasil 2. Department of Radiology and Oncology - Clinical Oncology Unit; Faculdade de Medicina da Universidade de São Paulo Instituto do Câncer do Estado de São Paulo (Icesp); Sao Paulo, Brasil 3. Department of Clinical Oncology - Hospital Sírio-Libanês; Sao Paulo, Brasil 4. Division of Neurosurgery, Hospital Sírio-Libanês; Sao Paulo, Brasil 5. Division of Neurosurgery, Santa Paula Hospital, São Paulo, SP, Brasil 6. Department of Oncology, Division of Radiation Oncology, Queen's University - Kingston Health Science Centre, Kingston, ON, Canada 7. Department of Radiology and Oncology, Division of Radiation Oncology, Instituto do Câncer do Estado de São Paulo (Icesp), Faculdade de Medicina da Universidade de São Paulo, Sao Paulo, Brasil

8. Department of Radiation Oncology, Hospital Sírio-Libanês, Sao Paulo, Brasil
\end{abstract}

http://dx.doi.org/10.1590/1806-9282.65.3.460

\section{SUMMARY}

INTRODUCTION: Glioblastoma (GBM) is the most frequent primary malignant tumor from the central nervous system in adults. However, the presence of systemic metastasis is an extremely rare event. The objective of this study was to review the literature, evaluating the possible biological mechanisms related to the occurrence of systemic metastasis in patients diagnosed with GBM.

RESULTS: The mechanisms that may be related to GBM systemic dissemination are the blood-brain barrier breach, often seen in GBM cases, by the tumor itself or by surgical procedures, gaining access to blood and lymphatic vessels, associated with the acquisition of mesenchymal features of invasiveness, resistance to the immune mechanisms of defense and hostile environment through quiescence. CONCLUSIONS: Tumor cells must overcome many obstacles until the development of systemic metastasis. The physiologic mechanisms are not completely clear. Although not fully understood, the pathophysiological understanding of the mechanisms that may be associated with the systemic spread is salutary for a global understanding of the disease. In addition, this knowledge may be used as a basis for a therapy to be performed in patients diagnosed with GBM distant metastasis.

KEYWORDS: glioblastoma, systemic metastasis, distant metastasis, extracranial, extraneural.

\section{INTRODUCTION}

Glioblastoma multiforme (GBM) is the most common malignant tumor of the central nervous system (CNS) in adults, corresponding to $14.9 \%$ of primary tumors and $46.6 \%$ of primary malignant tumors of the central nervous system 1 . Data from The Central Brain Tumor Registry of the United States (CBTrus) have proven it to be more prevalent in Caucasian men and its incidence increases with age, being more common between the sixth and seventh decades of life. There is an estimate of 12,390 new cases in the year 2017; of these, 11,740 occur in people over 40 years old 1 .

DATE OF SUBMISSION: 02-Aug-2018

DATE OF ACCEPTANCE: 05-Aug-2018

CORRESPONDING AUTHOR: Gustavo Nader Marta

Rua Dona Adma Jafet, 91 - Sao Paulo - Sao Paulo - Brasil - 01308-050

Phone: (55 11) 33945367 - FAX: (55 11) 3155098

E-mail:gnmarta@uol.com.br 
In Brazil, in 2016, there was an estimate of 5,440 new cases of CNS cancer in men and 4,830 women. Disregarding non-melanoma skin tumors, CNS cancer in men is the 11th most frequent in the Southeast region. For women, it is the sixth most frequent in the Southern region. There are no specific histology data of the CNS tumor subtype in Brazil available².

The GBM is a tumor of high local aggressiveness, typically infiltrative and of rapid evolution, characteristically relapsing, resulting in limited prognosis. The survival of these patients progressed with the development of therapeutic protocols, especially the Stupp protocol in 2005, which added temozolomide (TMZ) to radiotherapy (RT) in the postoperative context and subsequent TMZ for six cycles, raising the overall survival (OS) in 2 years to $26.5 \%$, compared with only $10.4 \%$ of exclusive postoperative $\mathrm{RT}^{3}$. It was also evidenced the benefit of survival even for the age range of 60-70 years, and the methylation of the promoter of O-6-methylguanine-DNA methyltransferase (MGMT) was established as the main predictor of the benefit of the TMZ association ${ }^{4}$. Recently, the association of tumor-treating fields (TTF) and TMZ maintenance, after the surgical protocol, RT + adjuvant TMZ, has been suggested as a new standard of treatment after an update of the phase III study, showing a gain of OS for this group ${ }^{5}$. Tumor-treating fields are the administration of alternating electric fields of low and medium intensity $(200 \mathrm{kHz})$ via four electrodes placed on the hairless scalp and connected by cables to a portable generator. It must be used for 18 hours a day or more, and the electrodes must be changed twice per week ${ }^{6}$. The electrical fields generated hinder the formation of microtubules from the mitotic spindle on the metaphase, preventing the formation of the equatorial band, inducing cell vacuolization and failure of the mitosis in anaphase. In the telophase, they trigger dielectrophoretic movements of polar molecules and organelles during cytokinesis. Thus, it works as a mitotic inhibitor by selectively disrupting cell division, paralyzing mitosis and inducing apoptosis ${ }^{6}$. In view of all these recent therapeutic advances, still the overall survival (OS) in 2 years is $27 \%$, and in 5 years, from $5 \%$ to $10 \%{ }^{6}$.

The systemic dissemination of GBM is considered a rare event, occurring in only 0.2 to $0.4 \%$ of cases $^{7}$, and its most common sites are bones, lymph node chains, liver, and lungs ${ }^{8-10}$. The first description of an event was made by Davis, in 1928, who named the disease Spongioblastoma ${ }^{11}$.
An increase in reports of this type of case has been observed, particularly starting at the year $1994^{12}$, perhaps due to the evolution of diagnostic methods with computed tomography and high-resolution magnetic resonance imaging, as well as PET-CT. Perhaps also due to the gain of survival using combined treatments, which may have increased the likelihood of dissemination and clinical manifestation of previously occult metastases.

Pietschmann et al., in their systematic review, assessed articles published from 1928 to 2013 and found 109 eligible studies, with a total of 150 patients diagnosed with GBM systemic metastasis ${ }^{12}$. From the data of the survey carried out for this study, other 14 cases reports were found from 2014 to 2017, totaling 17 patients ${ }^{8,13-24}$. The authors demonstrated that the average time from the initial diagnosis to the metastasis was nine months; the average survival after the metastasis was six months ${ }^{12}$.

The present study aimed to perform a descriptive and analytical review of the literature to assess the possible biological mechanisms related to the occurrence of distant metastasis in patients with a diagnosis of GBM.

\section{RESULTS}

The exact reasons for the low occurrence of distant metastasis in patients with a GBM diagnosis are unknown.

Some authors speculate that patients with GBM, due to their low survival, do not have enough time for dissemination, neither to the neuraxis nor systemic. Furthermore, in some of the cases described in the literature, the systemic metastasis was not clinically detectable prior to death. Currently, autopsy is an uncommon procedure in cancer deaths, so the post-mortem diagnosis is unlikely ${ }^{25}$.

\section{THE GLYMPHATIC SYSTEM}

Until recently, it was believed that one of the factors hindering the exit of GBM cells from the CNS was the absence of a local lymphatic system. This concept was disproved after two independent laboratories, first the Kipnis ${ } \mathrm{ab}^{26}$ and then the Alitalo $\mathrm{lab}^{27}$, demonstrated the existence of lymphatic vessels in the meninges, baptized of glymphatic system. Such vessels were described as a network of narrow vessels that run along the blood vessels of the superior 
and transverse, sagittal sinus. This lymphatic network becomes denser at the base of the brain and exits the skull along with the cranial nerves. These lymph vessels likely drain into deep cervical lymph nodes (dCLN), since the injection of dye into the cerebrospinal fluid was detected in the light of the lymphatic vessels marked by receivers Lyve-1 and VEGFR3, and in the dCLN, and not in the blood vessels. The ligation of lymphatic afferent to the dCLN abolished the drainage of dye for these nodules and made the meningeal vessels engorged ${ }^{28}$. In fact, there have been reports of cases with cervical nodal metastases in the absence of recurrence in the surgical scar or even without any pre-existing surgical procedure ${ }^{29-31}$. GBM rarely invades the meninges, and it is possible that surgical procedures facilitate the access of tumor cells to the meningeal vessels ${ }^{32}$.

The presence of the blood-brain barrier (BBB) The blood capillaries of the SNC differ from the capillaries of the rest of the body because they are not just a layer of endothelial cells loosely connected to each other, they are strongly connected among themselves by tight junctions, surrounded by a dense layer of basal membrane, pericytes and extensions of astrocytes, forming a highly selective microfilter, which only allows the passage of very small molecules. This barrier would make it impossible for cells to pass through due to their size. However, one of the main characteristics of high-grade gliomas as GBM is the breaking of the BBB, routinely described in imaging examinations of these patients. Thus, perhaps this is not the main obstacle to the formation of metastases ${ }^{33}$.

It is understood that the tumor cells have access to blood circulation through the breaking of the BBB, but, as theorized by Liu et al. ${ }^{34}$ in the theory of circulating stem cell (SCS), the tumor cells need specific skills to spread. As occurs in other malignant tumors, there is a cellular subtype in the tumor mass representative of less than $5 \%$ of the tumor population, which has preserved its potential for renewal,

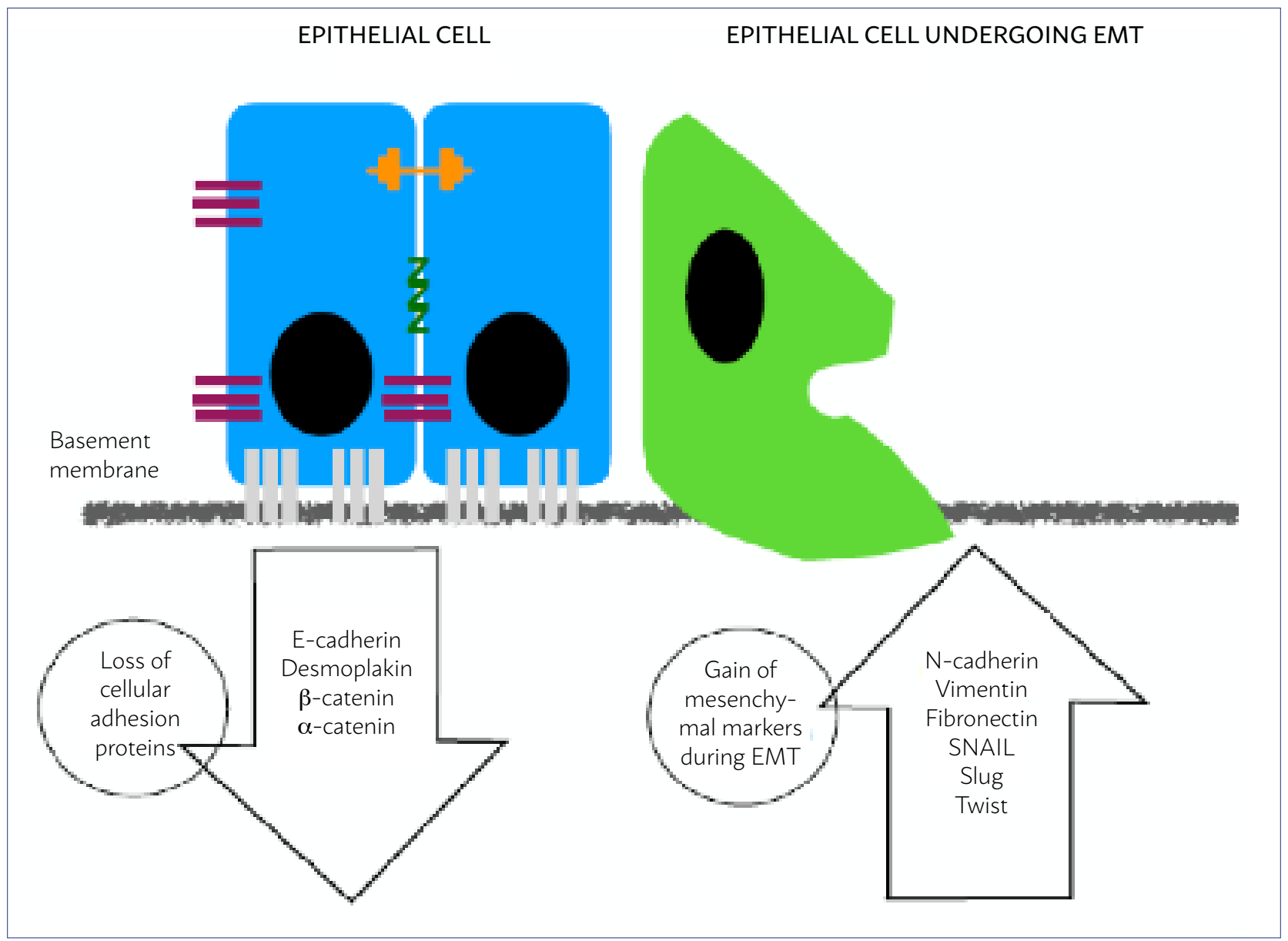

FIGURE 1: Changes in molecular markers during EMT. Loss of contact proteins: E-cadherin, Desmoplakin, $\beta$ and $\alpha$ Catenins. Gain of mesenchymal markers: N-cadherin, Vimentin, Fibronectin, SNAIL, Slug, and Twist. Adapted from Serrano-Gomez et al. Molecular Cancer (2018) 15:18 (39). 


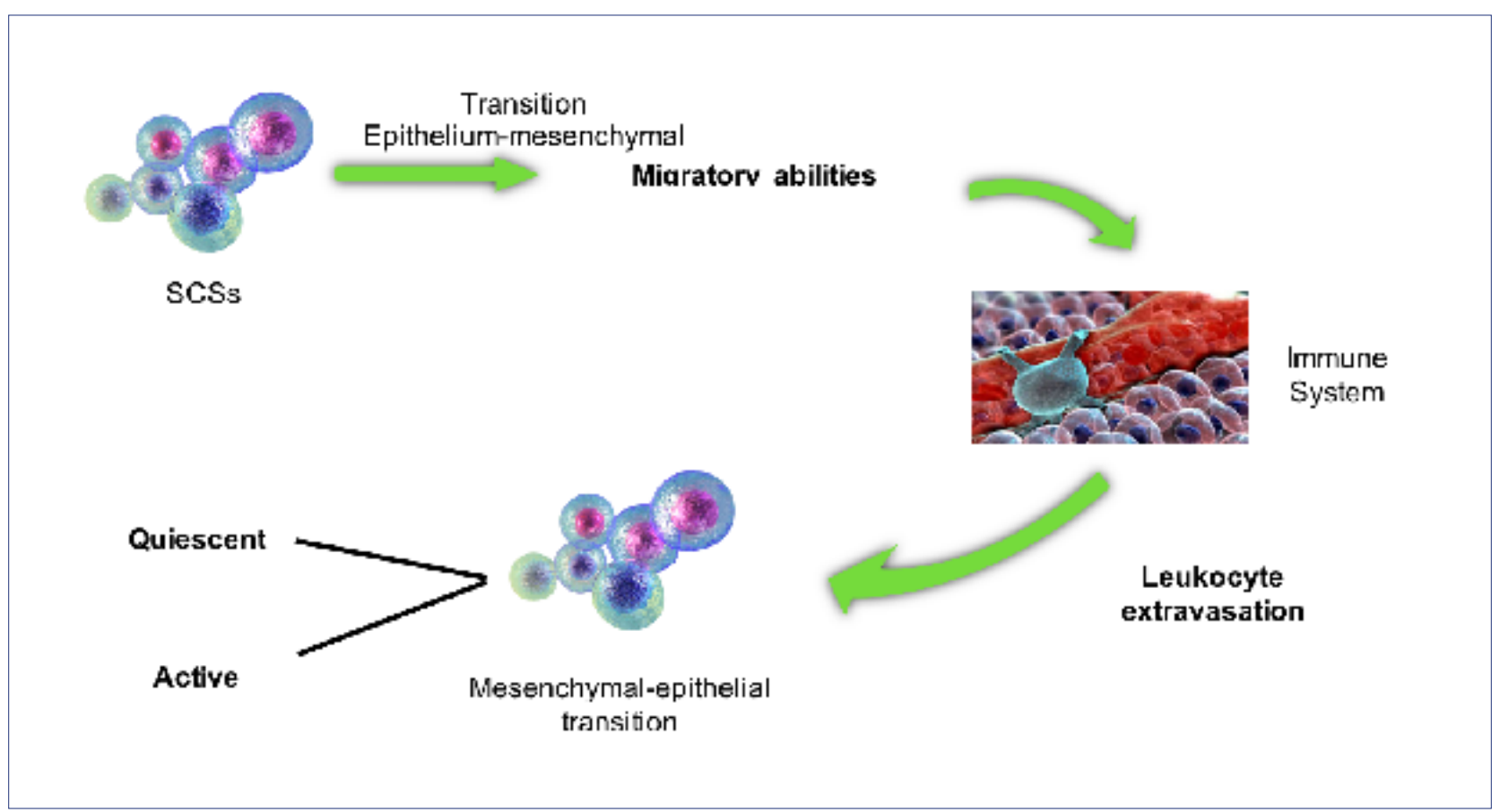

FIGURE 2. Scheme of the mesenchymal-epithelial transition.

is highly tolerant to hostile environments, to the defenses of the host and to the suppression of growth factors. They are the only cells capable of generating new tumors, the so-called cancer stem cells. Liu et al. hypothesized that these cells suffer a process of epithelial-mesenchymal transformation (EMT), acquiring skills for migration, such as the production of metalloproteinases and proteases enzymes capable of degrading the basal capillary membrane, allowing the breaking of the $\mathrm{BBB}^{34}$. Some of the EMT markers are: loss of epithelial markers and acquisition of mesenchymal cells, rupture of the intercellular adhesion, change of the apicobasal polarity and remodeling of the cytoskeleton. These changes are associated with the increase of cell migration and resistance to anoikis $^{33}$ (Figure 1).

Once in the bloodstream, the SCSs are subject to selection by shear stress and the immune system. It is argued that the SCSs can add to blood components such as platelets, "hiding" from the immune system and avoiding anoikis (programmed cell death by detachment from the extracellular matrix). The SCS exits the bloodstream through the capillaries of host tissue by the process of leukocyte extravasation. In the new environment, they go through a process reverse to the initial one, dependent on the absence of EMT inducer signs, the mesenchymal-epithelial transition (EMT), reassuming the initial epithelial phenotype, which may remain quiescent or multiply actively ${ }^{35}$ (Figure 2).
Thus, EMT and SCSs are closely related in the process of tumor progression, especially in the initial stages of metastasis, which involves the invasion of surrounding stroma and the hematogenous dissemination to organs such as the liver, lungs, and bones $^{36,37}$.

The emergence of new technologies for detecting SCSs has led to the concept of liquid biopsy, which is the study of SCSs or even pieces of DNA from tumor cells in peripheral blood. The liquid biopsy can be used to detect cancer at an early stage, outline a treatment plan and assess its success or detect molecular changes and, consequently, resistance to tumor therapy ${ }^{38}$.

An example of the EMT/EMT process is the sarcomatous metaplasia. It is the acquisition of a sarcomatous phenotype by neoplastic glial cells, allowing the acquisition of extracellular matrix of proteins necessary for vascular invasion. Gliosarcomas are more likely to invade the connective tissue, including the meninges. This transformation can be an undesired consequence of the GBM treatment, particularly RT and chemotherapy with alkylating agents, due to its potential to induce mutations on glial cells ${ }^{39}$.

Another way of breaking the BBB is through surgery. According to Houston et al., about $96 \%$ of extraneural metastases occur after a neurosurgical procedure $^{31}$. A craniotomy gives access to vessels of the cerebral parenchyma, meninges, and scalp. Ventriculoperitoneal shunts were also associated with 
dissemination, not only for the reason mentioned above but also by allowing the migration of cells through its lumen ${ }^{24}$. In a case report with a review of the literature published by Lewis et al., approximately 20 cases were found of GBM with recurrence in the surgical scar or adjacent soft tissues until $2015^{8}$. On this publication and so far it is not possible to say what is the exact mechanism for such an occurrence, or if the surgical technique plays some role in it, but it is possible that tumor cells with molecular skills to survive outside the CNS are sown.

\section{Suppression of the extracranial growth by the} immune system

The prerequisite for the formation of metastases is that tumor cells reach the bloodstream so that they can be "distributed" to other organs. This also applies to GBM. Muller et al. published a study that demonstrated the presence of circulating cancer cells originating from the GBM in the peripheral blood of patients. The cells were detected using an immunocytochemical method, through the analysis of glial fibrillary acidic protein (GFAP), and its origin was confirmed by genomic tests (CGC and FISH). In treatment-naive patients, peripheral blood samples were collected before, during and after the surgical procedure. As a control, 23 healthy patients and five patients with cerebral metastases were also tested. In total, 141 patients with GBM were tested; 29 were positive for GFAP (20.6\%). Only one patient in the control group tested positive for GFAP, demonstrating the high specificity of the test. Thirteen patients tested positive before the surgical procedure. This shows that the GBM cell can spread regardless of surgery. The mean follow-up time was 13.1 months, and no metastasis was detected ${ }^{40}$.

If the GBM cells have proved capable of overcoming resistance mechanisms to exit the CNS and, as mentioned in the previous paragraph, reaching the bloodstream, why are more metastasis not detected? Perhaps due to the absence of GBM chemoattractives in peripheral tissues? Or, more likely, due to the action of the immune system (IS)?25.

To discuss the relationship between cancer and the IS refers to the concept of immunosurveillance. Immunosurveillance was first hypothesized by Macfarlane Burnet and Lewis Thomas at the end of the 1950s, by stating that the immune system protects against the development of tumors by means of a pa- trolling of the body, eradicating cancer cells as soon as they appear ${ }^{41}$.

Evidence points to the existence of immunosurveillance: 1) Immunosuppressed individual, such as transplant patients on prolonged use of immunosuppressants, have a risk one hundred times greater of developing neoplasms ${ }^{42}$ and the more intense the suppression, the greater the risk ${ }^{43}$. There are case reports of GBM metastasis that developed in transplanted organs, but not in the donor ${ }^{44-51}$. 2) Cancer patients developing an immune response to the tumor that expresses molecularly identified antigens ${ }^{52}$. 3) Presence of tumor infiltrating lymphocytes (TIL) correlates with better survival in patients with melanoma, ovarian and colon cancer ${ }^{53-56}$. The paraneoplastic syndrome of neurological degeneration also demonstrates a spontaneous antitumor immunity ${ }^{57}$.

If the IS is able to destroy early tumor cells, why immunocompetent patients develop cancer? To answer this question, a second concept is necessary: immunoediting.

These are acquired phenotypic characteristics common to almost all of the lineages of cancer cells, which allow them to circumvent barriers to growth and development: 1) autonomous growth; 2) angiogenic capacity; 3) unlimited replication; 4) resistance to apoptosis; 5) irresponsiveness to the growth inhibiting signs and 6) ability to metastasize ${ }^{58}$.

However, none of these skills allows for escaping immunosurveillance. It was proposed then that tumors that arise in immunocompetent patients would have reduced immunogenicity if compared to those of immunodeficient patients. This was tested in a study using an animal model, and the results suggest that tumors that arise in the presence of normal lymphocytes are selected (edited) for their ability to withstand the antitumor lymphocyte response ${ }^{59}$. The IS can eradicate early tumors, but also promotes the development of immunoinvasive clones that support an immunologically intact medium, and this is the seventh phenotypic prerequisite for tumor development.

In gliomas, immunoediting is divided into three stages: 1) immunosurveillance or elimination, previously described; 2) balance, and 3) escape. The balance stage is a period of latency in the development of cancer, in which cells that were not eliminated during immunosurveillance remain in dynamic interaction with the IS in the tumor microenvironment. The evidence for the existence of this stage was demonstrat- 
ed in a study published in $2007^{60}$. The CNS is considered immunologically distinct from the rest of the body due to the presence of the BBB. Many studies have attempted to clarify the mechanisms of anti-glioma immunity. Friese et al. described the transforming growth factor (TGF- $\beta$ as a key molecule implicated in the reduced immune function of patients with gliomas responsible for the reduced expression of NKG2D in CD8+ T lymphocytes and NK cells through the serum and CSF in vitro ${ }^{61}$.

As a result of this stage, the tumor can be eradicated or persist in this state of balance and non-progression, or even surpass the immune pressure and become clinically manifest, moving on to the escape stage. The escape stage represents the failure of the antitumor immunity, which is no longer able to restrict the growth of the tumor. The main escape mechanisms are intrinsic tumor changes, in which the tumor cell is more difficult to recognized or dead; and extrinsic changes, which diminish the effective capacity of the IS ${ }^{41}$.

Inability of invading the extracranial connective tissue

As previously discussed, the SCSs disseminated to other anatomical sites have two options: to multiply actively forming a metastasis or become quiescent. The non-proliferative reversible state in which the cell remains "trapped" in their cell cycle in GO/G1 is called cellular quiescence. Intrinsic and extrinsic conditions of the microenvironment influence this process in a permissive or restrictive way $^{62}$. Quiescent cancer cells are usually resistant to chemotherapy ${ }^{63}$.

Confirmation of the existence of tumor quiescence was evidenced recently for gliomas. Endaya et al. failed to identify a fraction of quiescent cancer cells in a rat model with GBM. Ten years later, Naumov Ng et al. described that some cell lineages, including GBM, could not induce tumors in vivo for a long period ${ }^{64,65}$.

Almog et al. hypothesized that quiescent tumors suffer a stable genetic reprogramming when they pass to the rapid growth phenotype and performed a wide transcriptional genomic analysis in search of the underlying molecular mechanism of these alternating states for various tumor histologies, including GBM. The comparative analysis between the quiescent tumor and rapid growth phenotypes proved that some specific genes are hyper-expressed in all the lineages of sleeper cells studied (breast carcinoma, GBM, osteosarcoma, and liposarcoma). They are: thrombospondin (inhibitor of angiogenesis), angiomotin (mediator of angiogenic activity of endogenous angiogenic inhibitor angiostatin), tropomyosin, transforming growth factor h2 (TGF-h2) and insulin-like growth factor binding protein 5 (IGFBP-5). The EphA5 expression, in particular, is significantly increased in quiescent cells of GBM. Therefore, the functional category most affected in the genetic signature of quiescent cells is the angiogenesis ${ }^{66}$.

The ephrin tyrosine kinase family of receptors and its ligands are known for their participation in the embryonic and adult neurogenesis and angiogenesis. All the lineages of quiescent cells showed increased EphA5 RNA. In gliomas, the EphA5 expression revealed a correlation with the pathological degree. Their levels also lowered the more advanced the tumor stage was, having perhaps a suppressing role ${ }^{66}$.

Treatment of glioblastoma with systemic metastasis

Due to the scarcity of cases, it is not possible to pinpoint what is the standard treatment for patients diagnosed with metastatic GBM. The drugs most often used are temozolomide and nitrosoureas. Bevacizumab (a recombinant humanized monoclonal antibody that blocks the action of vascular endothelial growth factor A-VEGF) has also been used as a monotherapy or in combination with chemotherapeutic agents $^{39}$.

In their meta-analysis of 88 cases of systemic metastatic GBM, Lun et al. found that patients who received multimodal treatment with local surgery and radiotherapy, systemic treatment with chemotherapy and cerebrospinal shunt, when necessary, were the ones that showed higher mean survival compared to less intense treatments ${ }^{67}$.

Pietschmann et al. showed that only $40 \%$ of the cases evaluated had complete information about the treatment. The therapeutic approaches vary greatly, from exclusive palliative care to exclusive surgery, exclusive radiotherapy or chemotherapy alone, and various combinations of these methods. The authors also noted a greater predisposition for extra-CNS metastasis in young patients (average age of 42 years), often in good clinical conditions, suggesting a more aggressive treatment whenever possible, but remembering that there is no proven benefit of survival ${ }^{12}$. 


\section{FINAL CONSIDERATIONS}

There are several mechanisms to be overcome by tumor cells until a distant metastasis is formed. The first of these is that the tumor cells need to acquire the mesenchymal characteristics necessary to detach from their environment and erode the vascular basement membrane, without undergoing anoikis, overcoming the barriers of the CNS, among them the BBB. High-grade gliomas, such as GBM, characteristically break this barrier, and that is easily observed in imaging studies such as a MRI. Neurosurgical procedures also disrupt the $\mathrm{BBB}$, which may facilitate this process. The cancer cells can then reach the circulation, either by hematologic or lymphatic pathways, becoming SCSs. However, once in the bloodstream, there is the action of a second filter, the immune system.

In immunocompetent patients, a large part of the SCSs ends up being detected and killed by Natural
Killer cells (NK), while other few escape hiding from defense cells by binding to blood components such as platelets. To reach the connective tissue of the host organ, however, they can remain quiescent until the environmental conditions become favorable to its activation and proliferation. Immunocompromised patients, such as those who received organs or are in post-radiochemotherapy and develop systemic metastasis, indicate a clear relationship between the degree of competence of the immune system and such this type of event.

Although still not completely clear, the physiopathological understanding of the mechanisms associated with the systemic dissemination of GBM is important to the overall understanding of the disease. In addition, this knowledge can serve as a basis for selecting the therapy for patients with a diagnosis of GBM with distant metastasis.

\section{RESUMO}

INTRODUÇão: Glioblastoma (GBM) é o tumor maligno mais comum do sistema nervoso central em adultos. Entretanto, metástase a distância de GBM é um evento extremamente raro. O presente estudo teve o objetivo de realizar uma revisão da literatura para avaliar os possíveis mecanismos biológicos relacionados com a ocorrência de metástase a distância de pacientes com diagnóstico de GBM. RESULTADOS: Os mecanismos que podem estar relacionados com a capacidade de disseminação sistêmica do GBM são a quebra de barreira hematoencefálica (BHE) frequentemente vista em GBM, seja pela doença, seja por procedimentos cirúrgicos, dando acesso aos vasos sanguíneos e linfáticos, associada à aquisição de características mesenquimais de invasividade, resistência aos mecanismos de defesa do sistema imunológico e adaptação a hostilidades dos meios distantes por meio de quiescência.

CONCLUSÕES: As células tumorais necessitam vencer diversos obstáculos até a formação de uma metástase distante. Apesar de não totalmente esclarecido, o entendimento fisiopatológico dos mecanismos pelos quais podem estar associados à disseminação sistêmica do GBM é salutar para a compreensão global da doença. Além disso, esse conhecimento pode servir de base para a terapia a ser empregada diante do paciente com diagnóstico de GBM com metástase a distância.

PALAVRAS-CHAVE: Glioblastoma. Metástase sistêmica. Metástase a distância. Extraneural. Extracranial.

\section{REFERENCES}

1. Ostrom QT, Gittleman H, Xu J, et al. CBTRUS Statistical Report: Primary Brain and Other Central Nervous System Tumors Diagnosed in the United States in 2009-2013. Neuro Oncol. 2016;18(suppl_5):v1-v75.

2. Estimativa 2018: Incidência de câncer no Brasil. [cited 2018 March 10]. Available from: http://www.inca.gov.br/estimativa/2018/estimativa-2018. pdf.

3. Stupp R, Mason WP, van den Bent MJ, et al. Radiotherapy plus concomitant and adjuvant temozolomide for glioblastoma. N Engl | Med. 2005;352(10):987-996.

4. Stupp R, Hegi ME, Mason WP, et al. Effects of radiotherapy with concomitant and adjuvant temozolomide versus radiotherapy alone on survival in glioblastoma in a randomized phase III study: 5-year analysis of the EORTC-NCIC trial. Lancet Oncol. 2009;10(5):459-466.

5. Stupp R, Taillibert S, Kanner AA, et al. Maintenance Therapy With Tumor-Treating Fields Plus Temozolomide vs. Temozolomide Alone for Glioblastoma: A Randomized Clinical Trial. JAMA. 2015;314(23):25352543
6. Stupp R, Taillibert S, Kanner AA, et al. Effect of Tumor-Treating Fields Plus Maintenance Temozolomide vs. Maintenance Temozolomide Alone on Survival in Patients With Glioblastoma: A Randomized Clinical Trial. JAMA. 2017;318(23):2306-2316.

7. Beauchesne P. Extra-neural metastases of malignant gliomas: myth or reality? Cancers (Basel). 2011;3(1):461-477.

8. Lewis GD, Rivera AL, Tremont-Lukats IW, Ballester-Fuentes LY, Zhang Y), Teh BS. GBM skin metastasis: a case report and review of the literature. CNS Oncol. 2017

9. Senetta R, Cassoni P. Skin metastases of glioblastoma. In: Tumors of the Central Nervous System, Volume 2: Gliomas: Glioblastoma (Part 2). Hayat MA (Ed.). Springer, Dordrecht, The Netherlands, 143-149 (2011)

10. Laraqui L, Amarti A, Zouaidia F, Maher M, Kettani F, Saidi A. [Pulmonary metastasis from a glioblastoma. A case report]. Rev Pneumol Clin. 2001;57(3):225-228 
11. Davis L. Spongioblastoma Multiforme of the Brain. Ann Surg. 1928;87(1):814.

12. Pietschmann S, von Bueren AO, Kerber MJ, Baumert BG, Kortmann $\mathrm{RD}$, Muller K. An individual patient data meta-analysis on characteristics, treatments and outcomes of glioblastoma/ gliosarcoma patients with metastases outside of the central nervous system. PLoS One. 2015;10(4):e0121592

13. Kumar $V$, Singh $D$, Singh $H$, Saran RK. A case report of pontine glioblastoma presenting as subcutaneous metastasis in nape of neck in a child. J Pediatr Neurosci. 2015;10(4):386-388.

14. Johansen MD, Rochat P, Law I, Scheie D, Poulsen HS, Muhic A. Presentation of Two Cases with Early Extracranial Metastases from Glioblastoma and Review of the Literature. Case Rep Oncol Med. 2016;2016:8190950.

15. Xu M, Wang Y, Xu J, Yao Y, Yu WX, Zhong P. Extensive Therapies for Extraneural Metastases from Glioblastoma, as Confirmed with the OncoScan Assay. World Neurosurg. 2016;90:698 e697-698 e611.

16. Vandenbussche CJ, Ho CY, Nugent SL, Ali SZ. Extraneural metastases of primary central nervous system tumors identified by fine needle aspiration: a retrospective analysis. Acta Cytol. 2014;58(2):117-124.

17. Starnoni D, Yamgoue $Y$, Hottinger A, Bartanusz V. Multilevel severe radiculopathy from an extraneural glioblastoma cervical metastasis. Surg Neurol Int. 2016;7(Suppl 40):S1028-S1029.

18. Garcia JR, Corbella C, Baquero M, Bassa P, Soler M. Extracranial metastasis of multiforme glioblastoma detected by (11)C-methionine brain PET/ CT. Rev Esp Med Nucl Imagen Mol. 2017;36(4):271-272.

19. Kup PG, Nieder C, Winnekendonk G, Adamietz IA, Fakhrian K. Extracranial oral cavity metastasis from glioblastoma multiforme: A case report. Mol Clin Oncol. 2016;5(4):437-439.

20. Anghileri E, Castiglione M, Nunziata R, et al. Extraneural metastases in glioblastoma patients: two cases with YKL-40-positive glioblastomas and a meta-analysis of the literature. Neurosurg Rev. 2016;39(1):37-45; discussion 45-36.

21. Khattab MH, Marciscano AE, Lo SS, et al. Antiangiogenic Therapies and Extracranial Metastasis in Glioblastoma: A Case Report and Review of the Literature. Case Rep Oncol Med. 2015;2015:431819.

22. Undabeitia ], Castle M, Arrazola M, Pendleton C, Ruiz I, Urculo E. [Multiple extraneural metastasis of glioblastoma multiforme]. An Sist Sanit Navar. 2015;38(1):157-161.

23. Forsyth TM, Bi WL, Abedalthagafi M, Dunn IF, Chiocca EA. Extracranial growth of glioblastoma multiforme. I Clin Neurosci. 2015;22(9):1521-1523.

24. Narayan A, Jallo G, Huisman TA. Extracranial, peritoneal seeding of primary malignant brain tumors through ventriculo-peritoneal shunts in children: Case report and review of the literature. Neuroradiol J. 2015;28(5):536-539.

25. Mourad PD, Farrell L, Stamps LD, Chicoine MR, Silbergeld DL. Why are systemic glioblastoma metastases rare? Systemic and cerebral growth of mouse glioblastoma. Surg Neurol. 2005;63(6):511-519; discussion 519.

26. Louveau A, Smirnov I, Keyes T], et al. Structural and functional features of central nervous system lymphatic vessels. Nature. 2015;523(7560):337-341.

27. Aspelund A, Antila S, Proulx ST, et al. A dural lymphatic vascular system that drains brain interstitial fluid and macromolecules. J Exp Med. 2015;212(7):991-999.

28. Dissing-Olesen L, Hong S, Stevens B. New Brain Lymphatic Vessels Drain Old Concepts. EBioMedicine. 2015;2(8):776-777.

29. Zhen L, Yufeng C, Zhenyu S, Lei X. Multiple extracranial metastases from secondary glioblastoma multiforme: a case report and review of the literature. J Neurooncol. 2010;97(3):451-457.

30. Hata N, Katsuta T, Inoue T, et al. [Extracranial metastasis of glioblastoma to the lung and heart with a histological resemblance to small cell carcinoma of the lung: an autopsy case]. No Shinkei Geka. 2001;29(5):433-438.

31. Houston SC, Crocker IR, Brat DJ, Olson JJ. Extraneural metastatic glioblastoma after interstitial brachytherapy. Int | Radiat Oncol Biol Phys. 2000;48(3):831-836

32. Mondin V, Ferlito A, Devaney KO, Woolgar JA, Rinaldo A. A survey of metastatic central nervous system tumors to cervical lymph nodes. Eur Arch Otorhinolaryngol. 2010;267(11):1657-1666.

33. Savagner P. Epithelial-mesenchymal transitions: from cell plasticity to concept elasticity. Curr Top Dev Biol. 2015;112:273-300.

34. Liu J, Lin PC, Zhou BP. Inflammation fuels tumor progress and metastasis. Curr Pharm Des. 2015;21(21):3032-3040.

35. Lombard A, Goffart N, Rogister B. Glioblastoma Circulating Cells: Reality, Trap or Illusion? Stem Cells Int. 2015;2015:182985.
36. Nieto MA, Huang RY, Jackson RA, Thiery JP. Emt:2016. Cell. 2016;166(1):2145.

37. Thiery JP, Acloque H, Huang RY, Nieto MA. Epithelial-mesenchymal transitions in development and disease. Cell. 2009;139(5):871-890.

38. Lianidou ES. Gene expression profiling and DNA methylation analyses of CTCs. Mol Oncol. 2016;10(3):431-442.

39. Ray A, Manjila S, Hdeib AM, et al. Extracranial metastasis of gliobastoma: Three illustrative cases and current review of the molecular pathology and management strategies. Mol Clin Oncol. 2015;3(3):479-486.

40. Muller C, Holtschmidt J, Auer M, et al. Hematogenous dissemination of glioblastoma multiforme. Sci Transl Med. 2014;6(247):247ra101.

41. Dunn GP, Fecci PE, Curry WT. Cancer immunoediting in malignant glioma. Neurosurgery. 2012;71(2):201-222; discussion 222-203.

42. Penn I. Why do immunosuppressed patients develop cancer? Crit Rev Oncog. 1989;1(1):27-52.

43. Penn I. The changing pattern of posttransplant malignancies. Transplant Proc. 1991;23(1 Pt 2):1101-1103.

44. Nauen DW, Li QK. Cytological diagnosis of metastatic glioblastoma in the pleural effusion of a lung transplant patient. Diagn Cytopathol. 2014;42(7):619-623.

45. Armanios MY, Grossman SA, Yang SC, et al. Transmission of glioblastoma multiforme following bilateral lung transplantation from an affected donor: case study and review of the literature. Neuro Oncol. 2004;6(3):259263.

46. Colquhoun SD, Robert ME, Shaked A, et al. Transmission of CNS malignancy by organ transplantation. Transplantation. 1994;57(6):970-974.

47. Frank S, Muller J, Bonk C, Haroske G, Schackert HK, Schackert G. Transmission of glioblastoma multiforme through liver transplantation. Lancet. 1998;352(9121):31.

48. Jonas S, Bechstein WO, Lemmens HP, Neuhaus R, Thalmann U, Neuhaus P. Liver graft-transmitted glioblastoma multiforme. A case report and experience with 13 multiorgan donors suffering from primary cerebral neoplasia. Transpl Int. 1996;9(4):426-429.

49. Morse JH, Turcotte JG, Merion RM, Campbell DA, Jr., Burtch GD, Lucey MR. Development of a malignant tumor in a liver transplant graft procured from a donor with a cerebral neoplasm. Transplantation. 1990;50(5):875877.

50. Ruiz JC, Cotorruelo JG, Tudela V, et al. Transmission of glioblastoma multiforme to two kidney transplant recipients from the same donor in the absence of ventricular shunt. Transplantation. 1993;55(3):682-683.

51. Val-Bernal F, Ruiz JC, Cotorruelo JG, Arias M. Glioblastoma multiforme of donor origin after renal transplantation: report of a case. Hum Pathol. 1993;24(11):1256-1259.

52. Jager D, Stockert E, Gure AO, et al. Identification of a tissue-specific putative transcription factor in breast tissue by serological screening of a breast cancer library. Cancer Res. 2001;61(5):2055-2061.

53. Mihm MC, Jr., Clemente CG, Cascinelli N. Tumor infiltrating lymphocytes in lymph node melanoma metastases: a histopathologic prognostic indicator and an expression of local immune response. Lab Invest. 1996;74(1):43-47.

54. Clark WH, Jr., Elder DE, Guerry Dt, et al. Model predicting survival in stage I melanoma based on tumor progression. J Natl Cancer Inst. 1989;81(24):1893-1904.

55. Sato E, Olson SH, Ahn f, et al. Intraepithelial CD8+ tumor-infiltrating lymphocytes and a high CD8+/regulatory $T$ cell ratio are associated with favorable prognosis in ovarian cancer. Proc Natl Acad Sci U S A. 2005;102(51):18538-18543.

56. Ohtani H. Focus on TILs: prognostic significance of tumor infiltrating lymphocytes in human colorectal cancer. Cancer Immun. 2007;7:4.

57. Dalmau |, Rosenfeld MR. Paraneoplastic syndromes of the CNS. Lancet Neurol. 2008;7(4):327-340.

58. Hanahan D, Weinberg RA. The hallmarks of cancer. Cell. 2000;100(1):5770.

59. Mombaerts P, lacomini J, Johnson RS, Herrup K, Tonegawa S, Papaioannou VE. RAG-1-deficient mice have no mature B and T lymphocytes. Cell. 1992;68(5):869-877.

60. Koebel CM, Vermi W, Swann JB, et al. Adaptive immunity maintains occult cancer in an equilibrium state. Nature. 2007;450(7171):903-907.

61. Friese MA, Wischhusen J, Wick W, et al. RNA interference targeting transforming growth factor-beta enhances NKG2D-mediated antiglioma im- 
mune response, inhibits glioma cell migration and invasiveness, and abrogates tumorigenicity in vivo. Cancer Res. 2004;64(20):7596-7603.

62. Senft D, Ronai ZA. Immunogenic, cellular, and angiogenic drivers of tumor dormancy--a melanoma view. Pigment Cell Melanoma Res. 2016;29(1):27-42

63. Adamski V, Hempelmann A, Fluh C, et al. Dormant glioblastoma cells acquire stem cell characteristics and are differentially affected by Temozolomide and AT101 treatment. Oncotarget. 2017;8(64):108064-108078.

64. Endaya BB, Lam PY, Meedeniya AC, Neuzil J. Transcriptional profiling of dividing tumor cells detects intratumor heterogeneity linked to cell prolif- eration in a brain tumor model. Mol Oncol. 2016;10(1):126-137.

65. Naumov GN, Bender E, Zurakowski D, et al. A model of human tumor dormancy: an angiogenic switch from the nonangiogenic phenotype. J Natl Cancer Inst. 2006;98(5):316-325.

66. Almog N, Ma L, Raychowdhury R, et al. Transcriptional switch of dormant tumors to fast-growing angiogenic phenotype. Cancer Res. 2009;69(3):836-844.

67. Lun M, Lok E, Gautam S, Wu E, Wong ET. The natural history of extracranial metastasis from glioblastoma multiforme. I Neurooncol. 2011;105(2):261-273. 